\title{
MICROPROPAGATION OF EUCALYPTUS NITENS MAIDEN (SHINING GUM)
}

\author{
FILOMENA GOMES ${ }^{1}$ AND JORGE M. CANHOTO ${ }^{2} *$ \\ ${ }^{1}$ Departamento Florestal, Escola Superior Agrária de Coimbra, Bencanta, 3040 Coimbra, Portugal \\ ${ }^{2}$ Instituto do Ambiente e Vida, Departamento de Botânica, Faculdade de Ciências e Tecnologia, \\ Universidade de Coimbra, Calçada Martim de Freitas, 3001-455 Coimbra, Portugal
}

(Received 7 February 2002; accepted 27 September 2002; editor S. A. Merkle)

\begin{abstract}
Summary
Eucalyptus nitens Maiden (shining gum) is a frost-tolerant species of Eucalyptus that can be used as an alternative species to Eucalyptus globulus in some regions of Portugal where winter temperatures are too low. Seedlings and 1-yr-old shoot tips and nodes were used for micropropagation of $E$. nitens. The best multiplication rate (2.25) was obtained when seedling shoots $(<15 \mathrm{~mm}$ ) were cultured on a medium containing the major nutrients (at half-strength) and minor elements of Murashige and Skoog (1962) medium, the organics of De Fossard medium (De Fossard et al., 1974) and a combination of benzyladenine $(0.9 \mu M)$ and 1-naphthaleneacetic acid $(0.05 \mu M)$. Seedling cuttings (4-, 8-, and 10-wk-old) rooted well on media containing several concentrations of 3 -indolebutyric acid $(4.9,9.8$, and $14.8 \mu M)$ or 3-indoleacetic acid (5.7, 11.4, and $17.1 \mu M$ ), giving frequencies of root induction above 80\%. With this type of explant, root formation was also found on basal medium without growth regulators. Rooting of in vitro-propagated shoots obtained from seedlings (8-wk-old) after four subcultures (every $3 \mathrm{wk}$ ) was more difficult, with the best results obtained on a medium containing $14.7 \mu M$ 3 -indolebutyric acid (60.0\% root induction). No root formation was achieved when shoots from 1-yr-old explants were used. After a period of 4 mo., $96.3 \%$ of the plants transferred to the greenhouse survived acclimatization.
\end{abstract}

Key words: shining gum; shoot proliferation; rooting; acclimatization.

\section{INTRODUCTION}

The genus Eucalyptus includes several economically important species, mainly for pulp and paper production (McComb and Bennett, 1986). Eucalypts originated from Australia and during the 19th century were introduced in several regions of the world (McComb et al., 1996) where they became dominant species (McVaugh, 1963). In Southern Europe, Eucalyptus culture is now widespread, especially in Spain and Portugal. In Portugal the total area occupied by Eucalyptus plantations is about 700000 ha (DGF, 2000 ), corresponding to $21 \%$ of the country's forested area, ranking third after Pinus pinaster (29\%) and Quercus suber (22\%). The most cultured species of Eucalyptus in Portugal is E. globulus, commonly known as Tasmanian blue gum. However, this species is quite sensitive to low temperatures, and in colder regions freezing can cause serious damage. In these areas, other species or hybrids showing more tolerance towards freezing could be an important alternative to $E$. globulus plantations (Gomes, 2000). One of these species is E. nitens (silver top or shining gum), which may occasionally reach a height of $90 \mathrm{~m}$ (Brooker and Kleinig, 1983). According to several authors, E. nitens is relatively frost tolerant (De Little et al., 1992; Volker et al., 1994). Field experiments performed in France, Portugal and Spain have shown that E. nitens trees grow well in regions $(600-1000 \mathrm{~m}$ altitude) where winter

*Author to whom correspondence should be addressed: Email jorgecan@ ci.uc.pt temperatures are too low for E. globulus growth (Goes, 1985). In addition, $E$. nitens produces a pulp of high quality, probably due to its lower density compared to E. globulus (Orme et al., 1993).

For large-scale Eucalyptus multiplication, conventional propagation techniques are still the most efficient approach (Trindade, 1996). However, propagation through cuttings is cumbersome, and rooting of mature cuttings is quite difficult (Hartney, 1981). According to McComb and Bennett (1986), micropropagation may be a valuable alternative when: (1) conventional propagation is difficult to achieve, (2) problems of rejuvenation exist, and (3) pressure to increase multiplication rates occurs. Several micropropagation techniques such as somatic embryogenesis (Muralidharan and Mascarenhas, 1995; Canhoto et al., 1999), organogenesis (Lakshmi Sita, 1979; Diallo and Duhoux, 1984; Lainé and David, 1994; Azmi et al., 1997; Arezki et al., 2000; Nugent et al., 2001), and axillary shoot proliferation (Gupta et al., 1983; Blomstedt et al., 1991; Chang et al., 1992; Sharma and Ramamurthy, 2000) have been applied for in vitro multiplication of myrtaceous plants. Among these methods, axillary shoot proliferation is the most widely used for Eucalyptus clonal propagation. Previous reports of $E$. nitens micropropagation have been published by Hartney (1981), Hartney and Baker (1980), and Williams et al. (1992). Protocols for somatic embryogenesis (Bandyopadhyay and Hamill, 2000) and organogenesis induction (Bandyopadhyay et al., 1999) have recently been developed.

This paper reports the micropropagation and acclimatization of E. nitens from aseptically germinated seedlings and from 1-yr-old 